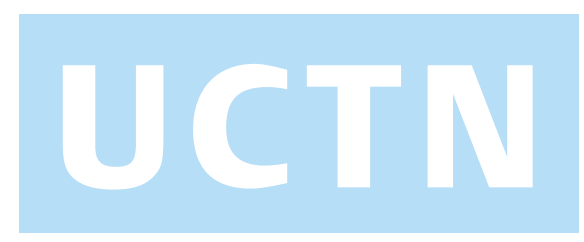

During our clinical practice of polypectomy we noticed that it was difficult to control the direction and size of the snare wire used in resection, because the force applied to open the wire acts only in the forward direction. Only the skill of the surgeon can then be applied to maneuver and surround the polyp. Starting from this point, we designed a device (Figure $\mathbf{1}$ ) in which the applied force acts in two directions, forward and sideways; the tip of the plastic cover is closed and the only way in which the wire can expand when it is pushed through a side window cut from the plastic cover, and its size can be controlled according to the polyp size. Therefore, we can now control the size of the snare wire and also the direction of its extension. After the polyp has been encircled we pull the snare wire, and its tip is released from the plastic cover (Figure $\mathbf{2}$ ). Another advantage is the steel collar which has been added at the near edge of the side window. This helps to make the

\title{
A Promising New Device for Use in Polypectomy
}

resection sharp and clean all the way round. We have applied our new snare wire to animal models with good results. We believe that we can use this snare wire for endoscopic gastric polypectomy or colonoscopic polypectomy and that we will be able to extend the use of the new snare wire to mucosal resection (Figure 2 ) $[1,2]$.

\section{F. S. Salameh}

Dept. or Surgery I, Tokyo Medical and Dental University, Tokyo, Japan

\section{References}

\footnotetext{
${ }^{1}$ Inoue $\mathrm{H}$, Tani $\mathrm{M}$, Nagai $\mathrm{K}$ et al. Treatment of esophageal and gastric tumors. Endoscopy 1999; 31: 47 - 55

${ }^{2}$ Inoue H, Takeshita K, Hori H et al. Endoscopic mucosal resection with a cap fitted panendoscope for esophagus, stomach, and colon mucosal lesions. Gastrointest Endosc 1993; 39: 58-62
}

\section{Corresponding Author}

\section{F. S. Salameh, M.D.}

Dept. of Surgery I

Tokyo Medical and Dental University

Ushima 1-5-45

Bunkyo-ku 113-8519

Tokyo

Japan

Fax +81-3-38187182

E-mail: salameh.srg1@tmd.ac.jp

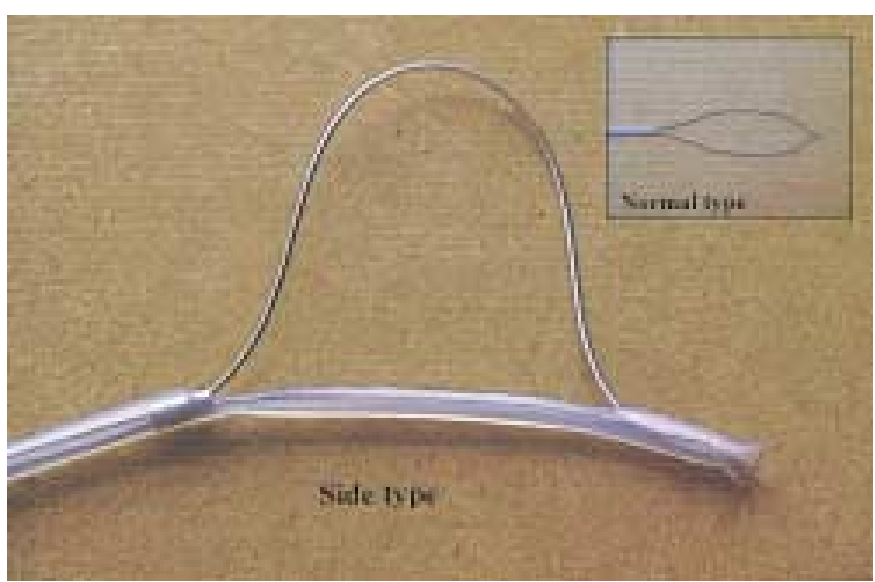

Figure 1 The new snare with closed plastic tip, side window, and metal collar

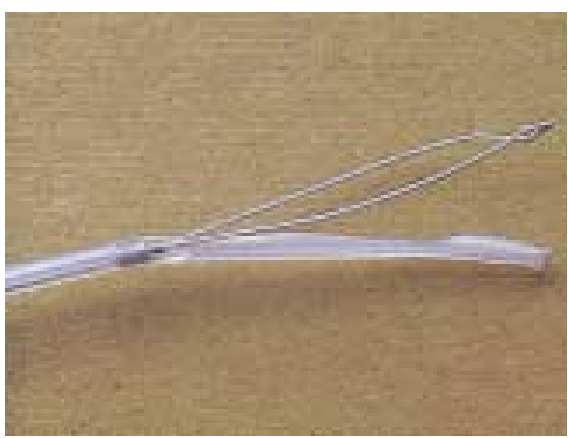

Figure 2 Side-type snare wire after the wire has been released from its plastic cover 